Matthias Dobbertin • Nadine Hilker •

Martine Rebetez • Niklaus E. Zimmermann •

Thomas Wohlgemuth • Andreas Rigling

\title{
The upward shift in altitude of pine mistletoe (Viscum album ssp. austriacum) in Switzerland—the result of climate warming?
}

Received: 29 September 2004 / Revised: 7 March 2005 / Accepted: 10 March 2005 / Published online: 5 May 2005

(C) ISB 2005

\begin{abstract}
Pine mistletoe (Viscum album ssp. austriacum) is common in natural Scots pine (Pinus sylvestris L.) forests in the alpine Rhone Valley, Switzerland. This semi-parasite, which is regarded as an indicator species for temperature, increases the drought stress on trees and may contribute to the observed pine decline in the region. We recorded mistletoes on representative plots of the Swiss National Forest Inventory ranging from 450 to $1,550 \mathrm{~m}$ a.s.l. We found mistletoe on $37 \%$ of the trees and on $56 \%$ of all plots. Trees infested with mistletoe had a significantly higher mortality rate than non-infested trees. We compared the current mistletoe occurrence with records from a survey in 1910. The current upper limit, $1,250 \mathrm{~m}$, is roughly $200 \mathrm{~m}$ above the limit of 1,000-1,100 $\mathrm{m}$ found in the earlier survey 100 years ago. Applying a spatial model to meteorological data we obtained monthly mean temperatures for all sites. In a logistic regression mean winter temperature, pine proportion and geographic exposition significantly explained mistletoe occurrence. Using mean monthly January and July temperatures for 1961-1990, we calculated Skre's plant respiration equivalent (RE) and regressed it against elevation to obtain the RE value at the current mistletoe elevation limit. We used this RE value and temperature from
\end{abstract}

M. Dobbertin $(\bowtie) \cdot$ N. Hilker $\cdot$ N. E. Zimmermann

T. Wohlgemuth · A. Rigling

WSL Swiss Federal Institute for Forest, Snow and Landscape

Research,

Zürcherstrasse 111,

8903 Birmendsorf, Switzerland

e-mail: dobbertin@wsl.ch

Tel.: +1-510-6423725

M. Rebetez

WSL Swiss Federal Institute for Forest, Snow and Landscape Research,

CP 96,

1015 Lausanne, Switzerland

Present address:

M. Dobbertin

Division of Ecosystem Science, Department of Environmental

Science, Policy and Management, University of California,

Berkeley, CA 94720, USA
1870-1899 in the regression and found the past elevation limit to be at $1,060 \mathrm{~m}$, agreeing with the 1910 survey. For the predicted temperature rise by 2030 , the limit for mistletoe would increase above $1,600 \mathrm{~m}$ altitude.

Keywords Pine mistletoe $\cdot$ Respiration equivalent . Logistic regression $\cdot$ Pine decline $\cdot$ Climate change

\section{Introduction}

Scots pine (Pinus sylvestris L.) forests commonly cover the slopes of dry inner-alpine valleys of the European Alps. At lower altitudes in these valleys Scots pine occurs close to the southern limits of its natural range (Richardson 2000). In the Swiss Canton Valais these forests constitute $11 \%$ of the total forest area and reach from the valley floor at between 400 and $700 \mathrm{~m}$ to the sub-alpine forests at $2,000 \mathrm{~m}$ a.s.l. They perform multiple functions, such as protection against soil erosion, avalanches, and rock slides, are a source of timber, and are used for recreation (Rigling et al. 2004).

Unusually high tree mortality of Scots pine has recently been observed in several of these inner-alpine valleys (Cech and Perny 1998; Vertui and Tagliaferro 1998). In the Swiss Rhone Valley in Valais, up to half of the Scots pine died locally between 1995 and 2000. The exact causes of the present mortality episode have not been established and are currently under investigation (Dobbertin 1999; Rigling and Cherubini 1999; Rebetez and Dobbertin 2004; Rigling et al. 2004; Bigler et al. in press).

In Switzerland the temperature has increased at more than twice the global average in the 20th century (Begert et al. 2005). Most of the increase has happened during the last 20 years (Rebetez 1999, 2001; Frei et al. 2001). Rebetez and Dobbertin (2004) showed for the Swiss Rhone Valley, that summer temperatures have increased and that the number of warm days with mean temperature above $20^{\circ} \mathrm{C}$ has doubled over the last 20 years, possibly making the trees more susceptible to insect attacks and nematode or pathogen infections (Bale et al. 2002). Since pine growth in 
the Valais is strongly limited by high temperatures and rain shortage during summer (Kienast et al. 1987; Rigling et al. 2002, 2003; Weber et al., in press) the observed climate warming might have negative effects on pine vitality and reduce pine resistance against biotic stresses.

Scots pine trees in the Swiss Rhone Valley are frequently infested with pine mistletoe (Viscum album ssp. austriacum). Pine mistletoe occurs almost exclusively on pine species. Norway spruce trees are very rarely infected, and only if they grow in pine forests (Tubeuf 1923). Pine mistletoe is a hemi-parasite. It is able to photosynthesize but needs to take up water and nutrients from its host tree. The mistletoe uses the haustoria to tap the xylem water of its host tree (Calder and Bernhardt 1983). The nutrient uptake of the mistletoe requires a high amount of water and thus increases water stress in host trees. During a drought, when the tree reduces its transpiration rates by stomatal closure, the mistletoe continues to transpire and this increases the drought stress further (Fischer 1983). Mistletoe infection rates at low altitudes are currently very high in the Swiss Rhone Valley. In many stands $>80 \%$ of all pines are infected (personal observation). Research on long-term monitoring plots found significantly increased mortality rates and higher needle loss for infected pines following the drought of 1998 (Dobbertin 1999).

The pine mistletoe and its subspecies, V. album ssp. abietis and $V$. album ssp. album, are known to be temperature-sensitive (Tubeuf 1923; Skre 1979; Jeffree and Jeffree 1996). Mistletoes have therefore been used as climate indicators in paleo-climatological studies using pollen analysis (Iversen 1944; Troels-Smith 1960). Iversen (1944) found that the mistletoes are limited in their geographic distribution by both low summer and low winter temperatures. He used the temperature space described by the mean January and July temperatures to delineate the range of mistletoe occurrence. Skre (1971, 1979) found that the mean monthly temperatures of the coolest and the warmest month related closely to the heat sum that is needed as energy for the respiration and growth of evergreen plants (respiration equivalent; RE). He found that the temperature data of these 2 months described the limits of occurrence of $V$. album ssp. album.

$V$. album mistletoe subspecies do not reach the northern and the altitudinal limits of their host trees (Tubeuf 1923). In a survey of all Swiss forest districts in 1910, Coaz (1918) found that mistletoe occurred at up to approximately 1,000-1,100 $\mathrm{m}$ in the Swiss Rhone Valley, with the highest location found on a south-facing slope at 1,339 m, whereas Scots pine reaches an altitude of $>2,000 \mathrm{~m}$ in the same valley.

Mistletoe seeds are dispersed by various bird species (Tubeuf 1923). In the Swiss Rhone Valley, the main vector for seed dispersal is the mistletoe thrush (Turdus viscivorus). The mistletoe thrush occurs almost everywhere in Switzerland from lowlands to the timberline. It is known to winter in the warm inner-alpine valleys (Schmid et al. 1998).

In the Swiss Rhone Valley, neither the main host species nor the bird vector are limiting factors of the geographic distribution of the pine mistletoe. It is therefore an ideal location to study the effect of temperature and its observed increase on mistletoe occurrence.

The objectives of this study were therefore:

1. To compare the current geographic occurrence and extent of mistletoe with those of the 1910 survey.

2. To quantify the effect that mistletoe infestation has on its host tree by comparing the mortality rates of trees with and without high mistletoe infection.

3. To regress mistletoe occurrence against mean winter and summer temperatures for the period 1961-1990, including stand and site variables in the model.

4. To compute Skre's RE for all sites and to determine the actual minimum RE using a regression against altitude.

5 To find the past upper altitudinal limit of mistletoe by combining past temperature observations from a longterm climatic station in the Rhone Valley and the RE limit given by Skre's equation.

6. To predict the future altitudinal increase in mistletoe distribution using recent predictions of temperature increases.

\section{Materials and methods}

Study area and sampling methods

The study area of our investigation covered the Swiss Rhone Valley and its side valleys in the Canton Valais (Fig. 1). Based on the $1 \times 1-\mathrm{km}$ grid of the First Swiss National Forest Inventory 1983-1985 (LFI I; WSL 2002) and the Second Swiss National Forest Inventory (LFI II; Brassel and Brändli 1999) for 1993-1995, we selected all forest grid points up to $1,000 \mathrm{~m}$ and all plots with Scots pine up to $1,600 \mathrm{~m}$. Mistletoe is indeed not expected above this altitude. The circular sample plots consist of an inner and an outer circle. In the inner circle of $200 \mathrm{~m}^{2}$ all trees with diameter at breast height of at least $12 \mathrm{~cm}$, and in the outer circle of $500 \mathrm{~m}^{2}$ all trees with a minimum diameter at breast height of $36 \mathrm{~cm}$, were assessed (Stierlin et al. 1994). For all trees the diameter at breast height was measured and the status, viz standing or lying, living or dead, recorded. Trees that had been harvested or were missing since the last inventory were also recorded. On pine trees crown transparency was assessed as an indicator of tree vitality. Mistletoe abundance on pine trees was grouped into four classes: (1) no mistletoe, (2) little, (3) medium, and (4) severe mistletoe infestation. In the two national inventories pines had also been checked for mistletoe, but only trees with an infestation that either affected the tree vigor or the quality of the stem were classified as infected. All other trees were classified as not infected. Therefore the two methods were not directly comparable. However, the trees classified in the national inventories roughly coincide with the pines with medium and severe infestation in our inventory. The proportion of pines was computed for each plot. In addition, the slope and aspect of the plot were 
Fig. 1 Locations of sample plots in the Canton Valais, Switzerland

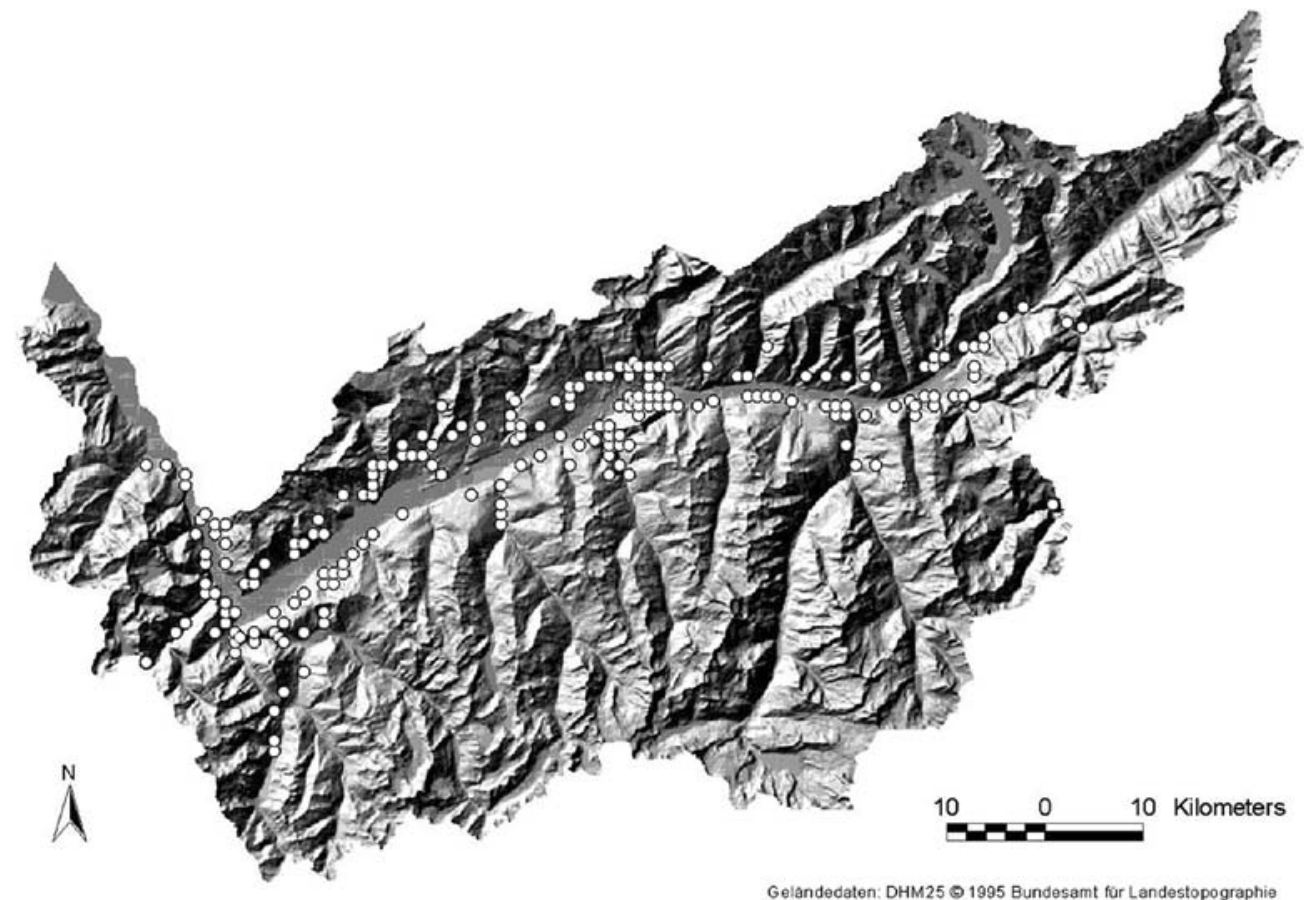

recorded and the density of the forest was classified into classes ranging from very dense to open.

Temperature modeling and calculation of the REs

For eight climate stations from the Swiss Meteorological Institute, MeteoSwiss, covering the whole range in altitude, mean monthly temperatures for the period 1961-1990 were first regressed against altitude. Based on this regression, values for each month were converted to sea level and spatially interpolated using the inverse distance weighted method in ArcInfo (Zimmermann and Kienast 1995, 1999). We overlaid the temperature maps with the geographic coordinates of the forest plots and obtained the monthly temperatures for each plot applying the obtained regression functions with the altitude of each plot. Mistletoe seedlings need around 3 years before the first leaf pair emerges. It can take $>10$ years before the plant becomes visible for terrestrial ground observation. Therefore, we used temperature records from the time when currently visible mistletoes became established (roughly before 1990) for our original model.

Past monthly temperature data for the period 1870-1899 were obtained from the station in Sion using the available homogenized temperature records. Assuming that the longterm temperature change was similar in the whole Rhone Valley, past monthly temperatures were extrapolated for all plots.

REs were estimated using Skre's regression model as a function of the mean January and July temperature (Skre 1971, 1979).

$\mathrm{RE}=0.575 \times T_{7}+0.101 \times T_{1}-2.77$ where $T_{7}$ is the mean July temperature and $T_{1}$ is the mean January temperature.

$\mathrm{RE}$ values were regressed against altitude and the value for the current mean upper mistletoe limit was used to obtain the current minimum RE value. Using the minimum RE value and the temperature estimate for July and January for the time period 1870-1899 and for a predicted future temperature rise up to the period 2020-2029, the past and future mistletoe limits were obtained.

\section{Statistical analysis}

We used statistics for proportions in cluster sampling as described in Cochran (1977) to estimate the mortality rates of trees classified with and without mistletoe in the first and second national inventory and to compute their $95 \%$ confidence intervals. We tested differences between the two populations using pair-wise $t$-tests.

A logistic regression model was used to predict the probability that mistletoe occurs at a site. Logistic regression models are ideal for binary response variables, such as the occurrence or non-occurrence of an event. They have frequently been used in tree mortality predictions (Monserud 1976; Monserud and Sterba 1999; Dobbertin and Brang 2001). The logistic regression model has the following form:

$\log (P /(1-P))=\alpha+\sum \beta_{I} \times x_{I}$

where $P=\operatorname{Pr}(Y=1 \mid x)$ is the probability of mistletoe occurring on a plot and $Y$ is the binary response variable $(Y=1$ if at least one tree in the plot has mistletoe and 
$Y=0$ otherwise), $\alpha$ is the intercept parameter, $\beta_{I}$ the slope parameters and $x_{I}$ the explanatory variable.

The LOGISTIC procedure in SAS software was used to fit the model (SAS Institute 1989). As a maximum likelihood estimate the $-2 \log$ likelihood was computed using the iteratively reweighted least squares algorithm (SAS Institute 1989). The likelihood ratio $\chi^{2}$-test statistics for the joint significance of the explanatory variables (Hosmer and Lemeshow 1989) are presented in this paper. Univariate tests based on the estimated covariance matrix of the maximum likelihood estimates were performed for the parameter estimates. The following variables were used in the regression: mean winter temperatures (December-February) or mean summer temperatures (June-August) for the period 1961-1990, proportion of pines on the plot in percent, and aspect (south- or west-facing slopes versus all other expositions). We used seasonal mean temperatures, because they appeared to give a more stable model fit than monthly mean temperatures.

\section{Results}

In 153 of the 201 plots surveyed in the inventory at least one living pine tree with a minimum diameter at breast height of $12 \mathrm{~cm}$ was found. The plots with pines in our sample ranged between $450 \mathrm{~m}$ and $1,550 \mathrm{~m}$. Above $1,600 \mathrm{~m}$ no plots were assessed. Altogether 945 living pine trees were surveyed for mistletoe occurrence. More than onethird $(36.7 \%)$ of the pines up to an altitude of $1,550 \mathrm{~m} \mathrm{had}$ mistletoes (Table 1). More than half of the pines $(53.5 \%)$ between 450 and $1,000 \mathrm{~m}$ were infected, while only $18.1 \%$ of the trees between 1,000 and $1550 \mathrm{~m}$ were infected. On $11.6 \%$ of the trees medium to heavy mistletoe infection was observed. The highest plot with at least one infected tree occurred at 1,490 m. Fifty-six percent of all plots had at least one infected tree. Up to an altitude of 1,000 m mistletoe was found on $65-85 \%$ of the plots (Fig. 2). Above $1,000 \mathrm{~m}$ mistletoe occurrence declined gradually. Up to an altitude of $1,250 \mathrm{~m}$ mistletoe was still found on more than half the plots which we defined here as the upper mean limit. Between 1,350 $\mathrm{m}$ and 1,450 m mistletoe occurrence declined sharply.

In the first national inventory (1983-1985) 9\% of all pine trees up to an altitude of $1,550 \mathrm{~m}$ a.s.l. were classified as mistletoe damaged and in the subset of plots assessed in the

Table 1 Number of living pine trees assessed and proportion of mistletoe (Viscum album ssp. austriacum) infection ratings above and below 1,000 $\mathrm{m}$ a.s.1.

\begin{tabular}{llllll}
\hline Altitude & $n$ & \multicolumn{4}{l}{ Mistletoe infection rate (\%) } \\
\cline { 3 - 6 } & & No & Light & Medium & Severe \\
\hline$\leq 1,000 \mathrm{~m}$ & 497 & 46.5 & 34.8 & 14.9 & 3.8 \\
$>1,000 \mathrm{~m}$ & 448 & 81.8 & 14.3 & 3.9 & 0.0 \\
Total & 945 & 63.3 & 25.1 & 9.6 & 2.0 \\
\hline
\end{tabular}

second national inventory (1993-1995) $21 \%$ of the pines were recorded with mistletoe damage (Table 2). Pine trees that were assessed as mistletoe damaged in the first or second national forest inventory had a mortality rate more than twice as high as pines without mistletoe damage, which was statistically significant (Table 2). Cutting rates of the pines with damage in the first national forest inventory were more than twice than for those trees without mistletoe damage and also statistically significant. Since the second national inventory no differences in cutting rates have been found. The combined rate of removed trees and trees that have died was also significantly higher for trees infested with mistletoe (Table 2). By comparing the mortality and cutting rates of all pines (29.2\%; data not presented in Table 2) with the rates of non-infested pines (26.4\%; Table 2) we found that mistletoe infestation accounted for roughly $10 \%$ (2.8\% out of $29.2 \%$ ) of removal and mortality of the pines in our sample.

The occurrence of mistletoe correlated closely with temperature (Fig. 3). Below a mean January temperature of $-3.7^{\circ} \mathrm{C}$ for the period $1961-1990$ no mistletoe occurred, and below a mean July temperature of $14.4^{\circ} \mathrm{C}$ only one plot with mistletoe was found.

In the logistic regression we used the three variables, winter temperature during the period 1961-1990, pine proportion and aspect (south- and west-facing slopes versus all other expositions). All three were significant (Table 3). For the range of values in our study area the likelihood of mistletoe occurrence increases with increasing winter temperature and to a small but significant extent on an increasing proportion of pines. Given the same temperature and pine proportions, mistletoe occurrence was more likely on south- or west-facing slopes than on other slopes (Fig. 4). A winter temperature difference of $1^{\circ} \mathrm{C}$ corresponds in the model to a difference in the probability of mistletoe of between 10 and $30 \%$, depending on the position of the curve. Likewise, pines growing on a south- or west-facing slope had a probability of mistletoe infection between 5 to $28 \%$ higher than pines growing on north- or east-facing slopes, depending on the mean winter temperature. When summer and winter temperatures were both used in a forward stepwise variable selection, winter temperature was selected by the model.

The RE values computed using the mean January and July temperatures also correlate highly with altitude (Fig. 5). In 1870-1899 the mean January temperature was $1.76^{\circ} \mathrm{C}$ colder, the mean July temperature $0.86^{\circ} \mathrm{C}$ colder, and the mean annual temperature $0.94^{\circ} \mathrm{C}$ colder than in the period 1961-1990. If the currently observed trend of the last three decades of temperature increase continued up to the period 2020-2029, another $2^{\circ} \mathrm{C}$ warming may be expected. For the current mean mistletoe altitude limit of $1,250 \mathrm{~m}$, a RE value of 5.6 was obtained using Eq. 1. Using this RE value and past temperature values, a past mean upper limit of $1,060 \mathrm{~m}$ and predicted future temperature increases, a future expected mistletoe limit of $1,680 \mathrm{~m}$ by the year 2040 was obtained (Fig. 5). 
Fig. 2 Proportion of plots with mistletoe (V. album ssp. austriacum) as a function of altitude. The proportion is computed for the plots up to $100 \mathrm{~m}$ below the given altitude

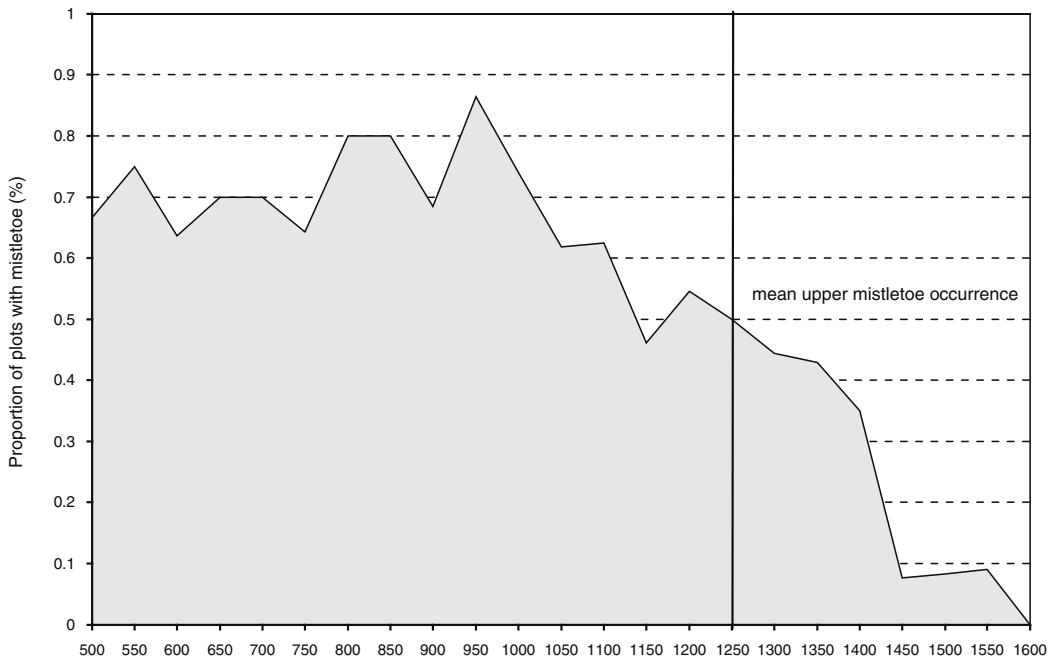

Altitude $(\mathrm{m})$

Table 2 Mortality and removal rates of Scots pine classified as infested by mistletoe (V. album ssp. austriacum) and not infested since the first (1983-1985) or the second (1993-1995) National Forest Inventory. The 95\% confidence interval (CI) of the estimate is also given

\begin{tabular}{|c|c|c|c|c|c|c|c|c|c|}
\hline \multirow[t]{2}{*}{ Inventory } & \multirow[t]{2}{*}{ Mistletoe } & \multirow[t]{2}{*}{ Trees $(n)$} & \multirow[t]{2}{*}{ Plots $(n)$} & \multicolumn{6}{|c|}{ Removal and mortality up to $2002 / 2003(\%)$} \\
\hline & & & & Removal & CI & Mortality & CI & Removal+mortality & $\mathrm{CI}$ \\
\hline \multirow[t]{2}{*}{ 1983-1985 } & No & 875 & 135 & $13.7 *$ & \pm 6.0 & $16.6^{*}$ & \pm 4.4 & $26.4 *$ & \pm 5.8 \\
\hline & Yes & 82 & 24 & $42.8 *$ & \pm 24.2 & $37.5^{*}$ & \pm 15.4 & $57.4 *$ & \pm 15.9 \\
\hline \multirow[t]{2}{*}{ 1993-1995 } & No & 525 & 90 & 5.9 & \pm 5.1 & $5.6^{*}$ & \pm 2.6 & $10.8^{*}$ & \pm 4.9 \\
\hline & Yes & 136 & 32 & 5.6 & \pm 5.4 & $21.7 *$ & \pm 12.4 & $25.2 *$ & \pm 13.4 \\
\hline
\end{tabular}

$* P<0.05$ (one-sided $t$-test)

Fig. 3 Occurrence of pine mistletoe (V. album ssp. January and July temperatures austriacum) in accordance with

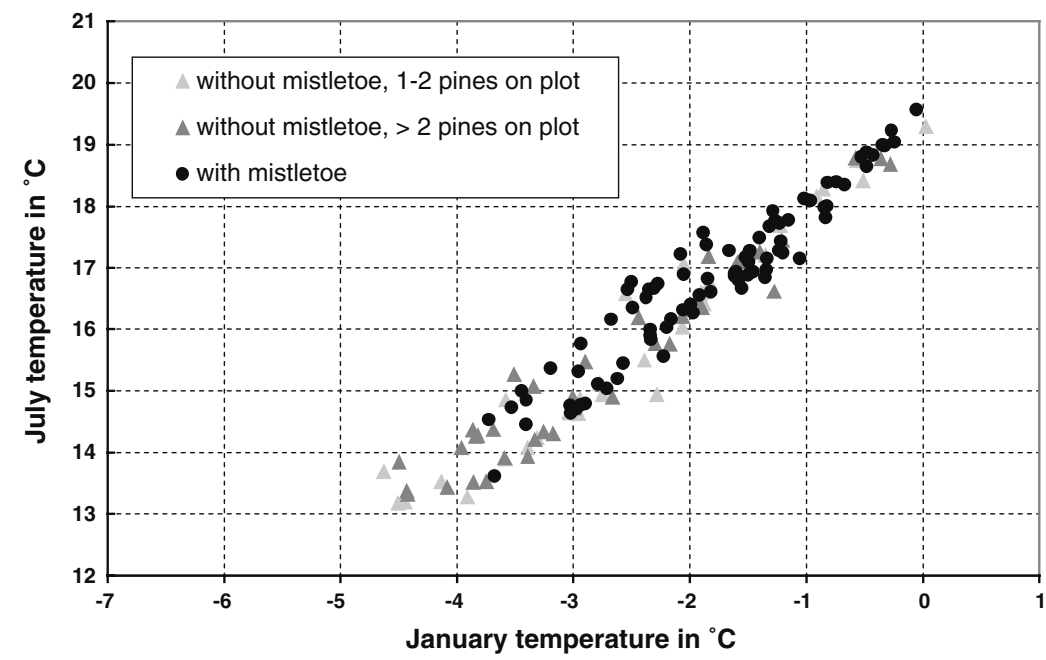

\section{Discussion}

In our study we found that a large percentage of pines were infested by mistletoe. In the geographic range examined, mistletoe occurred on roughly one-third of all trees and in half of all plots. Interestingly, for one location in the eastern part of the Rhone Valley, Coaz (1918) stated that mistletoe was not very common and not considered a threat to forest health because most pine forests there occur above $900 \mathrm{~m}$. We found, however, that, up to an altitude of 1,000 m, more than half of the trees were infested by mistletoe. We could also show that pines recorded with mistletoe damage in 1983-1985 and 1993-1995 were more likely to have died than non-infested pines. While many forest managers believe that pine mistletoe can cause or at least contribute to premature pine death, no study has confirmed this until now. For eucalyptus trees in Australia, Reid et al. (1994) found that trees with mistletoe had significantly higher mortality than trees where mistletoe had been removed. Dwarf mistletoe on conifers in North America has frequently been 
Table 3 Parameter estimates (Par. est.) for the logistic regression models with mistletoe (V.album ssp. austriacum) occurrence (yes/no) as response variable and mean winter temperature (1961-1990), pine proportions $(\%)$ and aspect (south and west $=1$, other aspects $=0$ ) as dependent variables $(P$-values for the overall model fit based on Wald $\chi^{2}$ were $\left.<0.0001\right)$

\begin{tabular}{llllll}
\hline Variables & $d f$ & $\begin{array}{l}\text { Par. } \\
\text { est. }\end{array}$ & SE & $\begin{array}{l}\text { Wald } \\
\chi^{2}\end{array}$ & $\begin{array}{l}\text { Probability } \\
>\chi^{2}\end{array}$ \\
\hline Mean winter temp & 1 & -0.91 & 0.03 & 1085.4 & 0.001 \\
Aspect & 1 & -0.63 & 0.06 & 100.1 & $<0.001$ \\
Pine proportion & 1 & -0.03 & $<0.01$ & 1501.8 & $<0.001$ \\
\hline
\end{tabular}

associated with increased tree mortality (Maffei et al. 1986; Filip et al. 1993). We found that, without pine mistletoe infection, mortality and tree removal would be roughly $10 \%$ lower, indicating that every tenth tree was cut or died due to mistletoe infection.

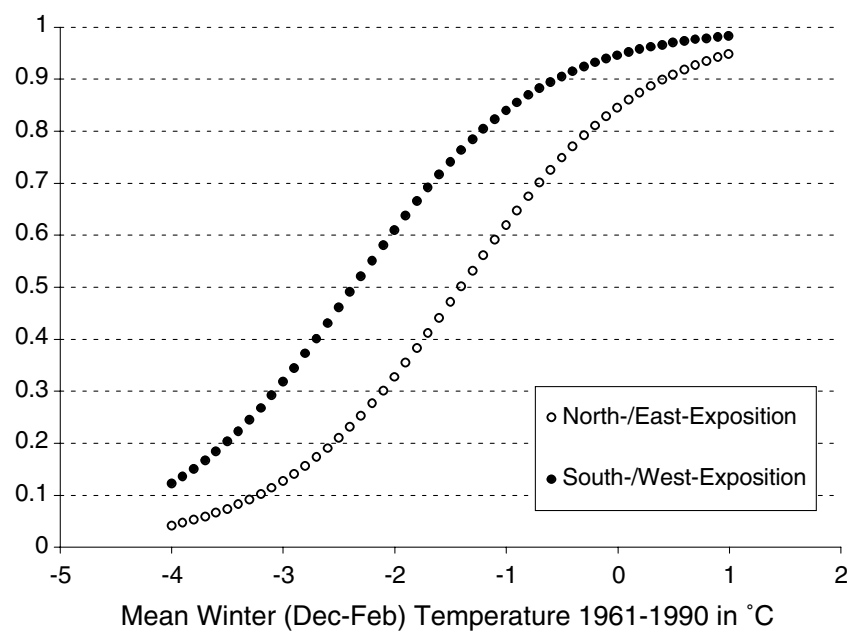

Fig. 4 Modeled probability of mistletoe (V. album ssp. austriacum) occurrence as a function of mean winter temperature [DecemberFebruary (Dec-Feb), 1961-1990] and slope exposition. Pine percentage was set to the approximate mean value of $50 \%$
The highest altitude at which we found mistletoe was $1,490 \mathrm{~m}$, which is the highest pine mistletoe location reported so far in Switzerland. It is $150 \mathrm{~m}$ higher than the record for the highest location from 1910 (Coaz 1918; Tubeuf 1923). The mean upper limit where the majority of the plots had at least one pine tree with mistletoe was $1,250 \mathrm{~m}$. This is roughly $200 \mathrm{~m}$ higher than the comparable limit in the 1910 survey (Coaz 1918). Logistic regression showed that winter temperatures were positively related to mistletoe occurrence and were more important than summer temperature. Interestingly, Skre's REs, which had originally been developed for Norway spruce [Picea abies (L.) Karst.], weight the July temperature 5 times higher than the January temperature (Skre 1979). From our study it seems that cold winters are more limiting for mistletoe than cool summers.

We found a RE value of 5.6 for $V$. album ssp. austriacum at the mean upper limit of $1,250 \mathrm{~m}$. This is lower than the RE value of 6.8 found for $V$. album ssp. album in Scandinavia (Skre 1979), indicating a lesser temperature sensitivity. This is surprising as $V$. album ssp. austriacum is described as the most temperature-sensitive of the three central European mistletoe subspecies (Tubeuf 1923). Its northern extension is further south than that of $V$. album ssp. album, while its range in altitude is below that of $V$. album ssp. abietis. For the alpine region with a longer vegetative period due to its topography, it is likely that either the RE relationship changes or the computed temperatures differ from those in forests. This could be shown from our data where the probability of mistletoe occurrence was higher on south- or west-facing slopes than on other slopes, given the same estimated mean winter temperature. Here either the interpolated temperature was not adequate or the higher radiation on sun-exposed slopes allows the temperature-sensitive mistletoe to occur at higher mean winter temperatures. Our highest site with mistletoe had a mean January temperature of $-3.7^{\circ} \mathrm{C}$ and a mean July temperature of $13.6^{\circ} \mathrm{C}$ for the period $1961-1990$. In comparison, Tubeuf (1923) reported the most northern pine mistletoe site close to the Baltic sea with a mean January
Fig. 5 Calculated respiration equivalents [RE (Re-value)] of sites with and without mistletoe (V. album ssp. austriacum) occurrence as a function of altitude for current, past and predicted future temperatures. Estimated RE limit for current upper mistletoe limit and predicted past and future mistletoe elevation limits

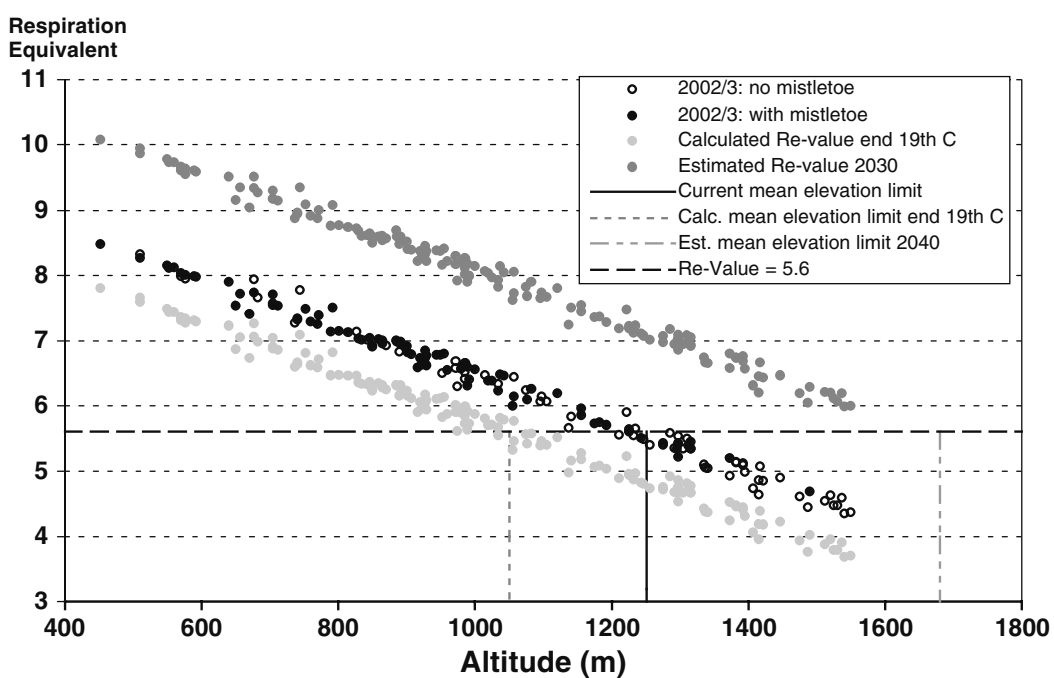


temperature of $-2.3^{\circ} \mathrm{C}$ and a July temperature of $13.7^{\circ} \mathrm{C}$. While this mean summer temperature was in close agreement with our data, the higher January temperature could also be due to the slope effect discussed earlier. The lowest temperature found for a site with mistletoes not on a southor west-facing slope was $-2.7^{\circ} \mathrm{C}$.

When an extrapolated mean temperature for the period 1870-1899 and the RE value of the mean current elevation limit of 1,250 m were used in Skre's equation, a past elevation limit of $1,060 \mathrm{~m}$ was obtained. This agrees with the survey by Coaz (1918). It is therefore reasonable to assume that the observed increase in temperature, in particular the increase in mean winter temperature of $1.6^{\circ} \mathrm{C}$, caused this shift. In Switzerland the increase in temperature is about twice the global average (Rebetez 2001). The minimum temperature in winter has risen more than the mean temperature (Rebetez 2001). As it is believed that minimum temperature in winter is one of the main limiting factors for mistletoe (Iversen 1944), the past increase may have favored mistletoe spread, in particular. In the 1990s the temperature rose even faster in Switzerland (Rebetez and Dobbertin 2004). The predicted future temperature rise, if correct, will eventually lead to a further shift of mistletoe distribution in altitude, as was shown by our regression. Jeffree and Jeffree (1996) predicted only a minor change in mistletoe occurrence in Great Britain using climate predictions and temperature ellipsoids formed by the mean temperatures of the warmest and coldest month. However, in Great Britain's highly oceanic climate mistletoe is not limited by low winter temperature as is the case in the Swiss Alps, but seems to be absent from coastal areas with warmer winters (Jeffree and Jeffree 1996).

Pine mistletoe in the Swiss mountains is dispersed by birds, while the Scots pine seeds are wind dispersed. An upward shift of Scots pine trees due to climate warming is restricted as the light-demanding pine seedlings face competition from the existing shade-tolerant spruce forests. It can therefore be expected that the upper limit of mistletoe will shift faster than the possible upward shift of the pine forest limits. Therefore, mistletoe may approach the elevation limit of pine. With the data available, it was not possible to test whether the intensity of mistletoe infection has also increased. However, as the probability of mistletoe occurrence increases with increasing temperature it is most likely that the overall intensity has also increased.

Our study shows that infection of pines by pine mistletoe in the Swiss Rhone Valley is severe and accounts for one-tenth of the current mortality and of forced cutting rates. Current winter temperature was found to be significantly related to mistletoe occurrence. We have further shown that both the mean upper elevation limit of mistletoe infestation and the absolute maximum altitude found today are between 150 to $200 \mathrm{~m}$ higher than those reported in a survey undertaken 90 years ago. This can be explained by the observed increase in temperature during the last 90 years using the current and the modeled past REs of Skre. Thus mistletoe occurrence seems to be a good indicator of the ongoing increase in winter temperatures. The future predicted temperature rise is expected to further extend the range and intensity of mistletoe infection and to greatly increase the currently high water stress experienced by pine forests.

Acknowledgements This work has been financed in part by the Swiss Federal Office of the Environment, Forests and Landscape (BUWAL, Bern) and Canton Valais. It was carried out within the framework of the Forest Dynamics Research Programme of the Swiss Federal Institute for Forest, Snow and Landscape Research (WSL, Birmensdorf). We are grateful to MeteoSwiss for providing the meteorological data, to the Swiss National Forest Inventory for providing the past inventory data, to Anne Herold for her helpful explanations on the mistletoe damage assessment of the forest inventory, to Freddy Potzinger and Raphael Siegrist for conducting the field assessments, and to Sylvia Dingwall for English corrections.

\section{References}

Bale JS, Masters GJ, Hodkinson ID, Awmack C, Bezemer TM, Brown VK, Butterfield J, Buse A, Coulson JC, Farrar J, Good JEG, Harrington R, Hartley S, Jones TH, Lindroth RL, Press MC, Symrnioudis I, Watt AD, Whittaker JB (2002) Herbivory in global climate change research: direct effects of rising temperature on insect herbivores. Global Change Biol 8:116

Bigler C, Bräker OU, Bugmann H, Dobbertin M, Rigling A (in press) Drought as an inciting mortality factor in Scots pine stands of the Valais, Switzerland. Ecosystems

Brassel P, Brändli U-B (eds) (1999) Schweizerisches Landesforstinventar. Ergebnisse der Zweitaufnahme 1993-1995Birmensdorf, Eidgenössische Forschungsanstalt für Wald, Schnee und Landschaft. Bundesamt für Umwelt, Wald und Landschaft. Haupt, Bern

Calder M, Bernhardt P (eds) (1983) The biology of mistletoes. Academic Press, Sydney

Cech T, Perny B (1998) Kiefernsterben in Tirol. Forstschutz Aktuell 22

Coaz J (1918) Über die Verbreitung der Mistel (Viscum album L.) in der Schweiz. Naturwiss Z Forst Landwirtsch 16:138-195

Cochran WG (1977) Sampling techniques, 3 edn. Wiley, New York

Dobbertin M (1999) Relating defoliation and its causes to premature tree mortality. In: Forster B, Knizek M, Grodzki W (eds) Methodology of forest insect and disease survey in Central Europe. Proceedings of the Second Workshop of the IUFRO WP 7.03.10, April 20-23, 1999, Sion-Châteauneuf, Switzerland. Swiss Federal Institute for Forest, Snow and Landscape, Birmensdorf, pp 215-220

Dobbertin M, Brang P (2001) Crown defoliation improves tree mortality models. For Ecol Manage 141:271-284

Fischer JT (1983) Water relations of mistletoes and their hosts. In: Calder M, Bernhard T (eds) The biology of mistletoes. Academic Press, Sydney, pp 163-184

Filip GM, Colbert JJ, Shaw CG, Hessburg PF, Hosman KP (1993) Influence of dwarf mistletoe and western spruce budworm on growth and mortality of Douglas-fir in unmanaged stands. For Sci 39:465-477

Frei C, Davies HC, Gurtz J, Schär C(2001) Climate dynamics and extreme precipitation and flood events in Central Europe. Integr Assess 1:281-299

Hosmer DW Jr, Lemeshow, S (1989) Applied logistic regression. Wiley, New York

Kienast F, Schweingruber FH, Braeker OU, Schaer E (1987) Tree-ring studies on conifers along ecological gradients and the potential of single-year analyses. Can J For Res 17:683-696

Iversen J (1944) Viscum, Hedera and Ilex as climate indicators. Geol För Förh Stockh 66:463-483 
Jeffree CE, Jeffree EP (1996) Redistribution of the potential geographical ranges of mistletoe and Colorado beetle in Europe in response to the temperature component of climate change. Funct Ecol 10:562-577

Maffei HM, Hawksworth F, Jacobi WR (1986) Growth and mortality effects of dwarf mistletoe on uneven-aged Ponderosa pine stands in Colorado. Phytopathology 76:1113-1113

Monserud RA (1976) Simulation of forest tree mortality. For Sci 22:438-444

Monserud RA, Sterba H (1999) Modeling individual tree mortality for Austrian forest species. For Ecol Manage 113:109-123

Rebetez M (1999) Twentieth century trends in droughts in southern Switzerland. Geophys Res Lett 26:755-758

Rebetez M (2001) Changes in daily and nightly day-to-day temperature variability during the twentieth century for two stations in Switzerland. Theor Appl Climatol 69:13-21

Rebetez M, Dobbertin M (2004) Climate change may already threaten Scots pine stands in the Swiss Alps. Theor Appl Climatol 79:1-9

Reid N, Yan ZG, Fittler J (1994) Impact of mistletoes (Amyema miquelii) on host (Eucalyptus blakelyi and Eucalyptus melliodora) survival and growth in temperate Australia. For Ecol Manage 70:55-65

Richardson DM (ed) (2000) Ecology and biogeography of pinus. Cambridge

Rigling A, Cherubini P (1999) Wieso sterben die Waldföhren im «Telwald》 bei Visp? Eine Zusammenfassung bisheriger Studien und eine dendroökologische Untersuchung. Schweiz Z Forstwes 150:113-131

Rigling A, Bräker OU, Schneiter G, Schweingruber FH (2002) Intra-annual tree-ring parameters indicating differences in drought stress of Scots pine forests within the Erico-Pinion in the Valais, Switzerland. Plant Ecol 163(1):105-121

Rigling A, Brühlhart H, Bräker OU, Forster T, Schweingruber FH (2003) Irrigation effect on tree growth and vertical resin duct production of Pinus sylvestris L. on dry sites in the Central Alps, Switzerland. For Ecol Manage 163:105-121

Rigling A, Weber P, Cherubini P, Dobbertin M (2004) Walddynamische Prozesse und Jahrringe-Bestandesdynamik zentralalpiner Waldföhrenwälder aufgezeigt anhand dendroökologischer Fallstudien aus dem Wallis. Schweiz Z Forstwes 155:178-190
SAS Institute (1989) SAS/STAT user's guide, version 6, vol 2, 4th edn. SAS Institute, Cary, N.C.

Schmid H, Luder R, Naef-Daenzer B, Graf R, Zbinden N (1998) Schweizer Brutvogelatlas. Verbreitung der Brutvögel in der Schweiz und im Fürstentum Lichtenstein 1993-1996. Schweizerische Vogelwarte Sempach

Skre O (1971) High temperature demands for growth and development in Norway Spruce [Picea abies (L.) Karst.] in Scandinavia. Meld Nor Landbrukshøgsk 51:1-29

Skre O (1979) The regional distribution of vascular plants in Scandinavia with requirements for high summer temperatures. Norw J Bot 26:295-318

Stierlin HR, Brändli, UB, Herold A, Zinggeler J (1994) Schweizerisches Landesforstinventar. Anleitung für die Feldaufnahmen der Erhebung 1993-1995. Eidgenössische Forschungsanstalt für Wald, Schnee und Landschaft, Birmensdorf

Troels-Smith J (1960) Ivy, mistletoe and elm: climate indicatorsfodder plants (a contribution to the interpretation of the Pollen Zone Border VII-VIII). Danmarks Geologiske UndersØgelse, IV. Raekke, Kopenhagen

Tubeuf von KF (1923) Monographie der Mistel. München, Berlin

Vertui F, Tagliaferro F (1998) Scots pine (Pinus sylvestris L.) die-back by unknown causes in the Aosta Valley, Italy. Chemosphere 36:1061-1065

Weber P, Rigling A, Bugmann H (in press) Differences in drought response of Pinus sylvestris L. and Quercus pubescens Willd, in the Swiss Rhone valley. In: Jansma E, Bräuning A, Gärtner $\mathrm{H}$, Schleser G (eds) TRACE. volume 2. Proceedings of the Dendrosymposium 2003. Schriften des Forschungszentrum Jülich, Jülich

WSL (2002) Schweizerisches Landesforstinventar LFI. Datenbankauszug der Erhebungen 1983-1985 und 1993-1995 vom 23.8.2002. Ulmer, Forschungsanstalt WSL, Birmensdorf

Zimmermann NE, Kienast F (1995) Das Klima lässt sich nicht kartieren-Klimakarten werden gerechnet. Informationsblatt Forschungsbereich Landschaftsökol 27:1-3

Zimmermann NE, Kienast F (1999) Predictive mapping of alpine grasslands in Switzerland: species versus community approach. J Veg Sci 10:469-482 